\title{
The Use and Functions of Mother Tongue in EFL Classes at the Language Center of South East European University in Tetovo-Macedonia
}

\author{
Basri Saliu \\ South East European University, Tetovo, Macedonia
}

\begin{abstract}
The use of mother tongue (L1) in foreign language classrooms at Language Center is obvious. In this paper, the use and functions of it in various classes have been analyzed and discussed. The purpose of the present study was to find out to what level the instructors use mother tongue in their classes. We attempted to find out whether their mother tongue use changes according to different variables, for which functions they use it, whether they are aware of the amount and the functions, whether the instructors are satisfied with the amount of $L 1$ they use, and whether their students are satisfied with it, and whether this satisfaction differs according to the amount used by their instructors. The study was conducted in the Language Center of South East European University in Tetovo, Macedonia, and it was based on both qualitative and quantitative research designs. The participants were 20 English teachers working in the Language Center and their 167 students. The data were collected through classroom recordings, questionnaires that were administered both to the instructors and the students, and interviews were conducted with all of the teachers and randomly chosen 49 students. The data have revealed that mother tongue is an indivisible part of language teaching, and it actually has different functions like "building up relations", "making the topic/meaning clear (by giving examples, explaining, making extra explanations, etc.)", "explaining difficult concepts or ideas", etc. It was also found out that both the instructors and the students were aware of the importance of using the target language as much as possible in the classes, however, they could not disagree with the need of mother tongue from time to time.
\end{abstract}

Keywords: Language Center; Use of mother tongue, Function of mother tongue; foreign language.

\section{Introduction}

The use of mother tongue (L1) has been a necessary part of second or foreign language teaching in different contexts where both the teachers and the learners have the same mother tongue. Despite the fact that it was prohibited at certain periods according to different language teaching methods such as Direct Method and Audio-lingual Method, it is allowed in various methods and approaches such as Natural Approach, Communicative Language Teaching, Task-Based Language Learning, etc.

Larsen-Freeman (2000, pp. 101-102) states that "the native language of the students is used in the classroom in order to improve the security of the students, to provide a bridge from the familiar to the unfamiliar, and to make the meanings of the target language words clear." Having various learning setting, most teachers are anxious about the use of mother tongue in the classes and cannot decide whether it is a good idea to use it or not, or if it is going to be used, when, why and for what purposes. In reality, the use of mother tongue may have a say to language learning process in various situations in the learning-teaching process; but still, the excessive use of it may result in too much reliance on it, which is not a wanted effect or outcome in the classes. According to Tang (2002), reasonable and thoughtful use of the mother tongue is supportive and can facilitate the learning and teaching of the target language. Schweers $(1999, p .7)$ argues that "starting with the L1 provides a sense of security and authenticate the learners' lived experiences, allowing them to express themselves. The learner is then willing to experiment and take risks with English." Teachers use L1 for the purpose of motivating students, helping students cope with some problematic situations, explaining some grammatical patterns (Duff \& Polio, 1990), explaining their ideas in writing composition or in oral work, and translating the reading passages (Patel and Jain, 2008; Nation, 2003). Also in many studies it has been reported that the use of $L 1$ is used for different other purposes in EFL or ESL classes: explaining the grammar, giving instructions, helping students/checking them, correcting the activities 
(Atkinson, 1987; Cook, 2001; Greggio \& Gil, 2007; Patel \& Jain, 2008). Moreover, using L1 helps maintain class discipline, build rapport and reduce social distance with students (Nation, 2003; Jingxia, 2009; Ramos, 2005).According to Moghadam et al. (2012), teachers use code change to check understanding, to clarify and to socialize. In addition, it is used to give the meaning of unknown vocabulary (Çelik, 2003; ùenel, 2010), which is found "economical and is a direct route to a word's meaning" (Thornbury, 1999, p.78).

Another important aspect of its use is the time saving. Atkinson (1987) focuses on time saving aspect of using L1 too; "a without delay 'How do you say X in English?' can often be less time consuming and can involve less potential uncertainty than other methods of eliciting such as visuals, mime, 'creating a need', etc." (p. 243). In addition, it arouses students' interest towards the lesson. However, the use of $L 1$ should not be exaggerated because the more the students are exposed to the target language, the better they will learn it. For this purpose, Atkinson (1987) points out the danger of overuse of the mother tongue in language classes which will lead to the translation of most language items into L1. Nation (2003) warns that using the mother tongue in the classroom reduces the amount of input and the opportunity of practice. Furthermore, Cook (2001) points out the importance of modeling the target language and encouraging L2 use. It is a reality that teachers may use the mother tongue in various situations for different purposes. Therefore, this study has tried to discover all these issues by collecting both qualitative and quantitative data. For this purpose we had some research questions as follows:

How much mother tongue (L1) do the instructors use in the classes and in which situations, and are they aware of it?

Are the instructors' use of $\mathrm{L} 1$ affected by different variables?

-Level of class

-Content of the course (Writing, reading, core language, listening \& speaking).

-Instructors' educational background

- Instructors' experience

What are the beliefs of the instructors regarding the use of L1 in the foreign language classrooms?

-Are these beliefs and the applications in the classes consistent?

-Do these beliefs differ according to the instructor related variables?

Instructors' experience.

Instructors' educational background.

-Do these beliefs differ according to the content of the course?

What are the beliefs of the students regarding the use of mother tongue in the foreign language classrooms?

- Do these beliefs differ according to the target language levels of the students?

Are the instructors satisfied with the amount of English they use in the classes, or do they want to use more or less than the present one?

Are the students satisfied with the amount of English their instructors use in the class or do they expect their them to use more or less English than the present situation?

\section{Methodology}

This study is a descriptive designed with mixed methods using with both qualitative and quantitative data. The study was conducted in the EFL classes that the instructors were teaching in the Language, South East European University. In the language center, the learners have to take the English courses for four semesters, with 6-8 hours of classes each week. The curriculum encloses fours levels of classes; elementary, pre-intermediate, intermediate and upper-intermediate. The decision as to which a student is going to attend an appropriate level is made through the placement test conducted at the beginning of the academic year. The core language course includes all four skills (listening, speaking, reading, and writing) 
and related grammatical patterns and vocabulary. The students at the same time continue with their main courses at their departments.

\subsection{Participants}

The participants in the study were 20 instructors who teach English and 167 learners studying English in the Language Center, South East European University University. In addition, the instructors had different educational backgrounds in terms of $\mathrm{BA}, \mathrm{MA}$ or PhD degrees that they held and all of them had language background. On the other hand, the students included in the study, were in twenty different groups with three different levels of English, namely, pre-intermediate $(51.7 \%)$, intermediate $(28.3 \%)$ and upper-intermediate levels $(19.9 \%)$. The students were grouped according to their placement test scores. The range of their age was between 19-22.

\subsection{Data collection}

For the purpose of the study, we had both qualitative and quantitative data: audio recordings of instructors in their classes, a questionnaire administered to instructors, a questionnaire administered to students, semi-structured interviews with 20 instructors and 39 students. The recordings were completed in about 8 weeks in each class. Each class hour lasted for about 50 minutes, and all 20 instructors (each one) were recorded 6 times in different courses, which is a totally 120 record. The instructors themselves audio recorded their classes. In addition, the questionnaires were designed to support up the data collected through the audio recordings. The questionnaires were adapted from various researchers who conducted similar research in the literature (Jingxia, 2008; Schweers, 1999; Duff \& Polio, 1990; Levine, 2003; Bateman, 2008; Cook, 2001). The first questionnaire intended at finding out the attitude of the instructors towards the use of $L 1$ in the classroom. The second questionnaire administered to the students aimed at finding out the amount of $L 1$ the instructors used in the classroom, and the students' perceptions about it. Both questionnaires were reviewed by some ELT experts and piloted. The questionnaire for instructors had Cronbach's alpha value of .90 , and the questionnaire for students had Cronbach's alpha value of 87 .

Additionally, the follow up interview sessions were conducted in order to back up the questionnaires and the audio recordings, and triangulate the data. The Interviews were semi-structured and conducted with 20 instructors and 29 students, who were composed of two randomly selected voluntary students from each instructor's classes.

\subsection{Data analysis}

The data collected through audio recordings in this study were analyzed by listening to the recordings and taking notes of the instances when the mother tongue was used by the instructors. Thus, the functions of the use of mother tongue have been categorized under various group headings/themes. The total use for each pre-determined category was marked. While listening to the recordings, if an extra category was decided, it was added in the table. Five of the recordings were also listened by two other instructors to ensure that the researchers were correctly categorizing the instances when mother tongue was used. The cases of $L 1$ use were marked and categorized as 51 items. They were also ranked from 1 to 51 .

The data collected through the questionnaires were analyzed through the Statistical Package for Social Sciences (SPSS) 16.0. First, the data were calculated by using Kolmogorov-Smirnov test whether they were parametric or non-parametric. It was calculated that some parts of the questionnaires were parametric and the others were nonparametric. Next, independent sample t-tests, two-way ANOVA, were used for parametric data, Mann-Whitney-U Test and Kruskal Wallis test for non-parametric data in order to find out whether there was a major variation between instructors' use of mother tongue and variables such as their educational background, teaching experience, gender, the level of the class they were teaching in. The results of the audio recordings were compared to the results of the questionnaires and to the answers given in the interviews in order to be able to see whether the instructors were aware of how much L1 they used in the classroom or not.

\section{Results and discussion}

Regarding the first research question as to how much $\mathrm{L} 1$ the teachers use in the classes and in which circumstances they use it and whether they aware of it, the results of the instructor questionnaire revealed that the instructors used L1 often to communicate with students outside the class. They usually used L1 for relationship building purposes (making jokes, 
showing concern to the students, showing empathy, etc.), to explain difficult impressions or ideas, to talk about organizational information (course policies, syllabi, assignements, announcements, deadlines, etc.), to explain grammar rules, and to talk about the exams (see Table 1). Th relationship building is one of the functions mentioned for which L1 is used in most of the studies done previously such as Schweers (1999), Saxena (2009), Al-Nofaie (2010), Bateman (2008).

On the other hand, what the instructors acknowledged about the use of L1 in their classes was different from what they actually performed in their classrooms. They stated that L1 was usually used for rapport building purposes (making jokes, showing concern to the students, showing empathy, etc.), but it was 45th place in the ranking list in the audio recording. Next, they stated that L1 was usually used to explain difficult concepts or ideas; however, it was in 49th

Table 1.The most frequent L1 use the instructors claim in the questionnaire, and the class recording results.

\begin{tabular}{|c|c|c|c|c|}
\hline Situation & Mean & SD & Level of Participation & The Rank in Recordings \\
\hline 21-To communicate with students outside the class & 4.40 & .68 & Often - & - \\
\hline $\begin{array}{l}\text { 25-For rapport building purposes. (Making jokes, } \\
\text { showing concern to the students,showing empathy, etc) }\end{array}$ & 4.00 & .86 & Usually & 45 \\
\hline 22-To explain difficult concepts or ideas & 3.95 & .89 & Usually & 49 \\
\hline \multicolumn{2}{|c|}{$\begin{array}{l}\text { 20-To talk about administrative information (course policies, } 3.80 \\
\text { announcements, deadlines, etc.) }\end{array}$} & .95 & Usually & 7 \\
\hline $\begin{array}{l}\text { 26. Because of time limitation. (I have to cover too much } \\
\text { material in a short time). }\end{array}$ & 3.50 & 1.00 & Usually & - \\
\hline 09. To explain grammar rules. & 3.45 & .89 & Usually & 9 \\
\hline 14. To talk about the exams. & 3.41 & .88 & Usually & - \\
\hline
\end{tabular}

Place in the ranking list. In addition, they also stated that $L 1$ was used to talk about administrative information (course policies, announcements, deadlines, etc.), which was the only item parallel with what they actually performed in the classroom (see Table 1). Although instructors had such beliefs regarding the L1 use, the actual use of $L 1$ in the classrooms was different. According to our data collected from class recordings, instructors used L1 to make the topic/meaning clear (by giving examples, explaining, making extra explanations, etc.), to present \& explain the topic, to give feedback, to teach the meaning of new vocabulary, to translate sentences that the instructor utters or those in the book/listening text without considering if it is understood or not, and to give/explain tasks or instructions (see Table 2).

Table 2. The recorded use of $L 1$ most in classes

\begin{tabular}{llc}
\hline Rank & Item $\quad$ Recorded Items & Tally \\
\hline 1 & 22 To make the topic/meaning clear (by giving examples, explaining, making extra explanations, etc.) & 896 \\
2 & 2 To present \& explain the topic & 474 \\
3 & 13 To give feedback & 378 \\
4 & 5 To teach the meaning of new vocabulary & 339 \\
5 & 48 To translate sentences that the instructor utters or those in the book/listening text without & 262 \\
& Considering if it is understood or not & 260 \\
\hline
\end{tabular}


During the interview, the instructors stated that they used L1 mostly in the grammar and the writing sections while they were explaining difficult parts of them. They also pointed out that they switched into L1 when they realized the students did not understand the topic/task/presented item, etc. For feedback, except one, all of the instructors claimed that they used $\mathrm{L} 1$ while giving feedback. $30 \%$ of the instructors stated that they directly used $\mathrm{L} 1$ for vocabulary teaching, but the others stated that they tried to explain the words in English, drew pictures, or acted out, etc. However, if the students still did not understand, then they used L1. All of the instructors emphasized that when they realized that the students could not understand, they used L1 to explain more or to translate. When giving/explaining tasks/instructions, some of them stated that they used L1 to explain the instructions. On the other hand, all of them pointed out that they used L1 to give homework in order to avoid students' complaint or any confusion among them. Greggio and Gil (2007), Morahan (2007), support this idea by pointing out that the key with teacher use of $L 1$ is that it is used for clarification purposes, after an attempt has been made to communicate ideas in L2, and students still appear to be confused. One of the students interviewed, S8, pointed out that since they sometimes did not understand when the explanations were in English, the teachers were forced to use Albanian/Macedonia by the students in class. Timucin and Baytar (2015) found out that teachers exploit L1 to translate when students do not understand, to check understanding, to explain procedures, to give directions, to explain grammar and to manage the class.

In addition, the instructors' claimed that they sometimes used L1 to explain what s/he aimed to tell the students, to catch the students' attention, and to explain the meaning of new words. They stated that they rarely used L1 to elicit English words or sentences (see Table 3).

Table 3.The least frequent $\mathrm{L} 1$ use the instructors claim in the questionnaire, and the class recording results.

\begin{tabular}{lcccc}
\hline Situation & Mean & SD & Level of Participation & The Rank in Recordings \\
\hline 08-To explain what I aim to tell my students. & 2.80 & 52 & Sometimes & 1 \\
18-To catch the students' attention. & 2.75 & .97 & Sometimes & 32 \\
10-To explain the meaning of new words. & 2.70 & .92 & Sometimes & 4 \\
17-To elicit English words or sentences. & 2.70 & .47 & Sometimes & - \\
12-To give instructions. & 2.55 & .94 & Rarely & 6 \\
\hline
\end{tabular}

On the other hand, what the instructors declared in the questionnaire was different from what they actually performed in their classrooms. Although they claimed that they sometimes used L1 to explain what s/he aimed to tell the students, it was in the 1st place in the ranking list. Next, they claimed that they sometimes used L1 to catch the students' attention, it was in the 32nd place in the ranking list. In addition, they stated that they sometimes used L1 to explain the meaning of new words, but it was in the 4th place in the ranking list. Another remarkable use of L1 was that they claimed that they rarely used L1 to give instructions; however, it was in the 6th place in the ranking list (see Table 3). Our class recordings revealed that the instructors were not aware how repeatedly they used $L 1$ for various purposes. As a matter of fact the instructors used L1 least for the purpose of talking about something that is not related to course; confirming students' understanding; conflict management; discussing course policies, attendance and other administrative information; transition from one topic to the other (OK, well, now, let's ....); and helping students find the correct answers for the questions \& activities in for the tasks in their textbooks (See Table 4).

Table 4. The recorded use of $\mathrm{L} 1$ least in classes

\begin{tabular}{lllc}
\hline Rank & Item & Recorded ltems & Tally \\
\hline 46 & 38 & Talking about something that is not related to course & 7 \\
47 & 15 & Confirming students' understanding & 6 \\
48 & 10 & Conflict management & 6 \\
49 & 20 & Discussing course policies, attendance and other administrative information & 4 \\
50 & 40 & Transitions (OK, well, now, let's ....)
\end{tabular}


The second research question focused on whether the instructors' use of L1 were affected by different variables such as level of students, the content of the course, educational background, and the experience of instructors. Our findings showed that there was no statistically significant difference regarding the level students $(p=0.357>0.05)$. However, the upper intermediate level had a rather low mean $(m=6.50)$, which showed that the use of $L 1$ fell down as the level increased. Qing (2010) has emphasized that "code-switching represents one of the strategies that EFL teachers often use to accommodate the students' level of English proficiency." (p. 112). Atkinson (1987) claims that "while giving instructions talking about the classroom methodology, while presenting and emphasizing the language, L1 is mostly used with the early stages of proficiency levels" (p. 244). Cole (1998) also claims that "the best use of L1 is with the beginning and low level students" (p. 2), which supports that L1 use in the classes differ according to the levels of the students. Regarding the

content of the course, only writing course was statistically significant $(p=0.03 \varepsilon 0.05)$ among core language, reading, writing and listening and speaking courses. Instructors claimed that they used L1 most in writing courses. Apart from this, the results in the recordings and the questionnaires support their argument. Our recording results showed that the instructors used L1 while teaching as to how to identify and write topic sentences, supporting sentences/ideas, paragraphs, thesis statements, and types of essays as well as giving feedback about their productions.

This result is in line with the results in the study of Stapa and Majid (2009) who claimed that when teachers use L1 in L2 writing classes with limited proficiency, students produce better quality essays. On the other hand, our statistical computation revealed that there was no statistically significant difference regarding instructors' educational background ( $p$ $=0.29>0.05)$, the degree the instructors held such as BA or MA ( $p=0.067>0.05)$, and the year of experience they had $(p=0.28>0.05)$. Our next research question was related to whether the attitude of instructors differ according to some variables such as instructors' know-how, instructors' educational background (ELT or Non-ELT, BA or MA degree), the content of the course. Our results showed that there was no statistically significant difference for instructors' practice $(p=$ $0.73>0.05)$, instructors' educational setting (ELT or Non-ELT, $(p=0.15>0.05)$, the degree the instructors held such as BA or MA $(p=0.76>0.05)$, and the content of the course $(p=0.067>0.05)$. This is parallel with the results of Oflaz (2009) and Moran (2009). The fourth research question focused on as to what the attitude of the students regarding the use of L1 were in the foreign language classrooms. Students totally approved that the more English they used, the better they would learn it $(\mathrm{m}=4.70)$. In addition, they agreed that they could help each other during the classes by using $\mathrm{L} 1(\mathrm{~m}=3.76)$; using English needed extra effort $(m=3.74)$; $\mathrm{L} 1$ should be used in order to talk about the class rules, attendance or organizational information in class $(m=3.72)$; use of $L 1$ aided comprehension $(m=3.69)$; in order to successfully acquire English, they should separate it from L1 $(m=3.57)$; they felt more contented about some functions or topics in $L 1$ rather than in English $(m=3.65)$; they could talk in L1in the class both with the instructors and with the students $(m=3.43)$. Students are aware of the importance of using target language in classes; however, they believed that they needed L1 for better grasp, to learn some key issues in grammar, and to discuss their problems in learning the target language. On the other hand, students totally opposed the item that when the instructor was too weary, s/he did not use English. In addition, they disagreed that they were used to the instructor's using $L 1$, and it was hard for them to change it $(m=2.40)$; the instructor and students should use only English to discuss course policies, attendance, and other administrative information $(m=2.36)$; there was no use in using English in the classroom $(m=2.23)$; they thought they did not understand when the instructor spoke in English $(m=2.18)$. Students also revealed that their instructors had a tendency to use the target language most of the time, and they expected them to use it because they stated that they could understand them when they spoke the target language to most extent. Our last research question was whether the instructors were satisfied with the amount of English they used in the classes, or whether they wanted to use more or less than the present one. The same question was asked to students, too. Among the instructors, $12.5 \%$ of them stated that they needed to use less English, $51.25 \%$ of them pointed out that they should keep the same amount they use at present although $36.25 \%$ stated that they needed to use more English in their classes. On the other hand, what students stated regarding the amount of use of $\mathrm{L} 1$ was parallel with the instructors. Among the students, $6.5 \%$ of them expected that the instructors should use less English, and $60.25 \%$ of them expected that the instructors should keep the present amount of L1. However, $36.25 \%$ of them expected more English in the classes, which is also parallel with the expectations of the instructors.

\section{Conclusion}

It is a good idea for sure to use L2 most of the time; however, teachers should also know that they should not feel at fault while using L 1 when it is really crucial and appropriate to do so. The situation might also be in the contrary way, that is, the 
teachers might be counting too much on $\mathrm{L} 1$, which provides less amount of target language input. In this study, we have found out that the instructors used L1 most for relationship building purpose, making the topic/meaning clear (by giving examples, explaining, making extra explanations, etc.), explaining difficult concepts or ideas, etc. However, they used it least for the purpose of talking about something that is not related to course; confirming students' understanding; conflict management; discussing course policies, attendance and other organizational information; transition from one topic to the other (OK, well, now, let's ....); and helping students find the correct answers for the questions \& activities in for the tasks in their textbooks. It was also found out that both the instructors and the students were aware of the importance of using the target language as much as possible in the classes, however, they could not disagree with the need of mother tongue from time to time. Both the instructors and students were satisfied about the amount of $L 1$ use in their classes.

Through this study, we hope that teachers will be able to see the situations in which the others use $\mathrm{L} 1$, and have better understanding concerning the role of $\mathrm{L} 1$ in their classes. This study may have an impact on teachers in terms of questioning their own L1 use, and being more aware of their own teaching. Teacher trainers may also make use of the present study while they are training the prospect teachers. They may explain that using the target language as much as possible should be the goal of every foreign language teacher, however, the use of the students' $\mathrm{L} 1$ might also be necessary from time to time, so it should not be a unthinkable for them. This study might create some awareness as to how much and for which task some teachers feel the need of using $\mathrm{L} 1$ in their classes. They might find some solutions for some of the functions for which L1 is used, and thus, teachers can use more of the target language, which will lead to more target language communication in their classes.

We had some hypothesis and limitations for the study. The participant instructors and their students were assumed to represent the population. The classes recorded in the study were assumed to follow the normal procedures that the instructors had while they were not recorded. In addition, the instructors were expected not to make any changes in their teaching. The answers given to the questionnaires and the interview questions both by the instructors and the students were assumed to be truthful and reflect their real thoughts and feelings honestly.

As for limitations, one of the limitations of the study was that it was not a repeated study. Although it was tried hard to have as many recordings as possible in order to make the instructors and students grow more used to to being recorded and to prevent them from conducting themselves, it was still not acceptable. Another limitation is that, since the study was conducted in the Langaueg Center, South East European University, the results were limited only to the instructors and students in this center. If it were applied in different universities, it could have some different results. A further study that will look into the same scope with the present study may use multidiciplinary studies and a higher number of participants. Furthermore, the participants may be asked why exactly they used L1 in the situations straight after the recordings to find out the real reasons for it. Moreover, further study may look into the students' use of L1 in L2 classrooms, too. Finally, a further study might also look into the effects of the use of L1 on the achievement of the students. Whether the use of L1 contributes to the achievement of the students or holds back it or whether the various functions of using L 1 help the students learn the target language better can be analyzed through a repeated study.

\section{References}

[1] Al-Nofaie, H. (2010). The attitudes of teachers and students towards using Arabic in EFL classrooms in Saudi public schools-a case study. Novitas-ROYAL (Research on Youth and Language). 4(1), 64-95.

[2] Atkinson, D. (1987). The mother tongue in the classroom: A neglected resource? ELT Journal, 41(4), 241-47.

[3] Bateman, B. E. (2008). Student teachers' attitudes and beliefs about using the target language in the classroom. Foreign Language Annals, 41 (1), 11-28.

[4] Cole, S. (1998). The use of L1 in communicative English classrooms. [Online] Retrieved on June 1, 2014 from http://jalt-publications.org/old_tt/files/98/dec/cole.html

[5] Cook, V. (2001). Using first language in the classroom. The Canadian Modern Language Review, 57(3), 402423.

[6] Duff, P. A., \& Polio, C. G. (1990). How much foreign language is there in the foreign language classroom? The Modern Language Journal, 74 (2), 154-166.

[7] Çelik, M. (2003). Teaching vocabulary through code-mixing. ELT Journal, 57 (4), 361-369.

[8] Greggio, S., \& Gil, G. (2007). Teacher's and learners' use of code switching in the English as a foreign language classroom: a qualitative study. Linguagem \& Ensino, 10, (2), 371-393. 
[9] Jingxia, L. (2009). Switching to L1 in the EFL classroom-the perspective of adaptation. The Open Applied Linguistics Journal, 2, 45-49.

[10] Larsen-Freeman, D. (2000). Techniques and principles in language teaching. New York: Oxford University Press.

[11] Moghadam, S. H., Samad, A. A., \& Shahraki, E. R. (2012). Code switching as a medium of instruction in an EFL classroom. Theory and Practice in Language Studies, 2 (11), 2219-2225.

[12] Qing, X. (2010). To switch or not to switch: examine the code-switching practices of teachers of non-English majors changer ou ne pas changer: examiner les pratique de l'alternance de code de l'enseignement de l'anglais pour les etudiants non-anglophones. Canadian Social Science,6, (4), 109-113.

[13] Ramos, F. (2005). Spanish teachers' opinions about the use of Spanish in mainstream English classrooms before and after their first year in California. Bilingual Research Journal, 29, (2), 411-433.

[14] Schweers, C.W. Jr. (1999). Using L1 in the L2 classroom. English Teaching Forum, 37(2), 6-9.

[15] Stapa, S. H.,\& Majid, A. H. A. (2009). The use of first language in developing ideas in second language writing. European Journal of Social Sciences, 7, (4),41-47. ùenel, M. (2010). Should foreign language teaching be supported by mother tongue? Journal of Language and Linguistic Studies, 6(1), 110-120.

[16] Tang, J. (2002). Using L1 in the English classroom. English Teaching Forum, 40 (1), 36-43.

[17] Thornbury, S. (2005). How to teach speaking. Malaysia: Pearson education Limited. 